\title{
P-Zn (Phosphorus-Zinc) System
}

\section{H. Okamoto}

The partial Zn-P phase diagram (0-70 at.\% Zn) in [Massalski2] was redrawn from [1991Dut].

The complete Zn-P phase diagram shown in Fig. 1 was calculated by [2009Tu] based on essentially the same experimental phase boundary data as [1991Dut]. The polymorphism of $\mathrm{Zn}_{3} \mathrm{P}_{2}$ and $\mathrm{ZnP}_{2}$ was not taken into account in the thermodynamic model. Transition temperatures of these compounds are shown in Fig. 1 as assessed by [1991Dut].
Table 1 shows Zn-P crystal structure data.

\section{References}

1991Dut: J. Dutkiewicz, The P-Zn (Phosphorus-Zinc) System, J. Phase Equilib., 1991, 12(4), p 435-438

2009Tu: H. Tu, F. Yin, X. Su, Y. Liu, and X. Wang, Experimental Investigation and Thermodynamic Modeling of the Al-P-Zn Ternary system, Calphad, 2009, 33, p 755-760

Table 1 Zn-P crystal structure data

\begin{tabular}{|c|c|c|c|c|c|}
\hline Phase & Composition, at. $\% \mathrm{P}$ & Pearson symbol & Space group & Strukturbericht designation & Prototype \\
\hline$(\mathrm{Zn})$ & 0 & $h P 2$ & $\mathrm{PG}_{3} / m m c$ & $A 3$ & $\mathrm{Mg}$ \\
\hline$\beta \mathrm{Zn}_{3} \mathrm{P}_{2}$ & 40 & $c^{* *}$ & $\ldots$ & $\ldots$ & $\ldots$ \\
\hline$\alpha \mathrm{Zn}_{3} \mathrm{P}_{2}$ & 40 & $t P 40$ & $P 4_{2} / n m c$ & $D 5_{9}$ & $\mathrm{P}_{2} \mathrm{Zn}_{3}$ \\
\hline$\beta \mathrm{ZnP}_{2}$ & 66.7 & $m P 24$ & $P 2_{1} / c$ & $\ldots$ & $\mathrm{ZnAs}_{2}$ \\
\hline$\alpha \mathrm{ZnP}_{2}$ & 66.7 & $t I 24$ & $P 4_{1} 2{ }_{1} 2$ & $\ldots$ & $\ldots$ \\
\hline$(\alpha \mathrm{P})$ & 100 & $c^{* *}$ & $\cdots$ & $\cdots$ & $\cdots$ \\
\hline
\end{tabular}

Weight Percent Phosphorus

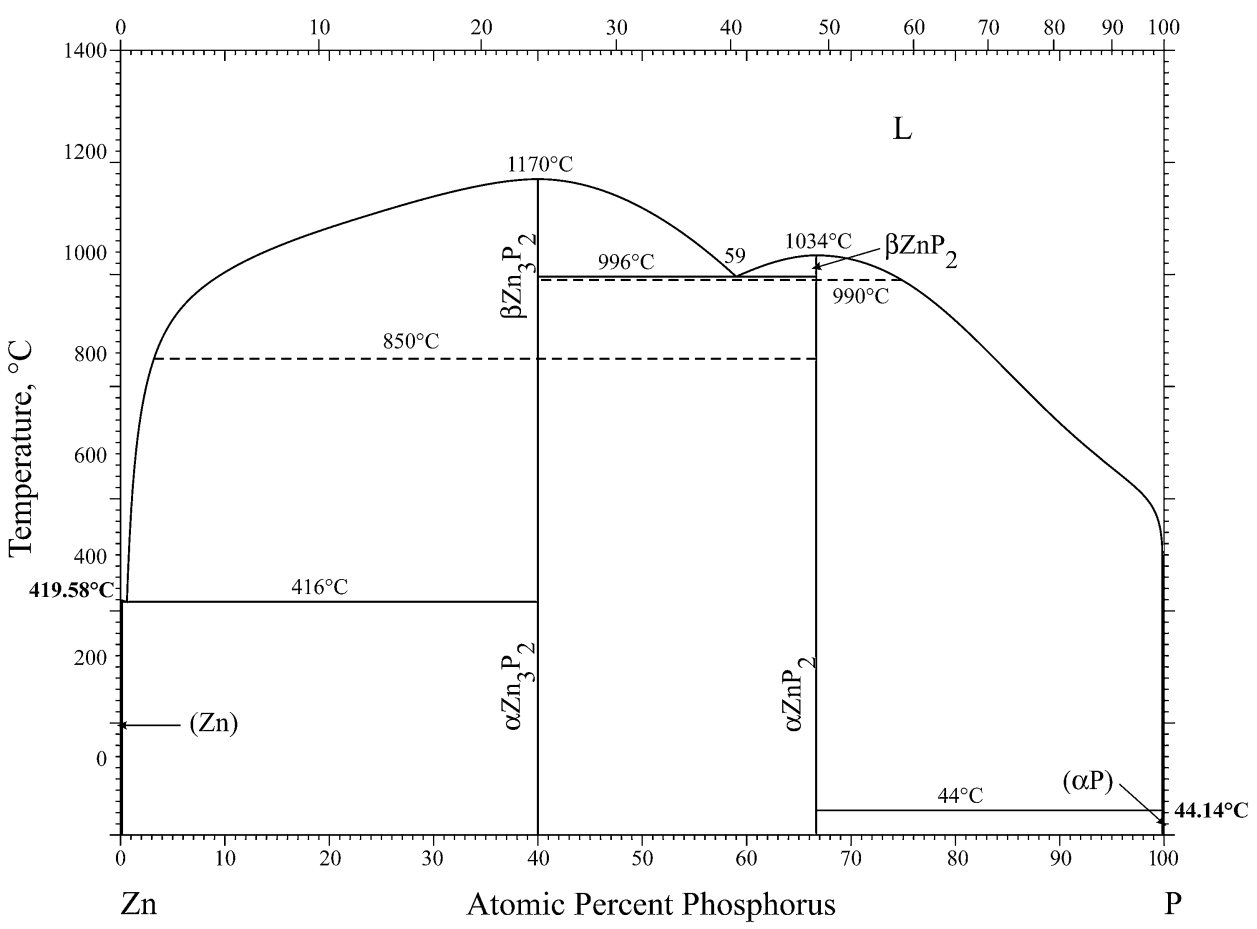

Fig. 1 Zn-P phase diagram 